\title{
Contribuição ao estudo da cárie dentária em crianças de 0-30 meses
}

\section{Contribution to the study of dental caries in 0-30-month-old infants}

\author{
Sandra Garrido de BARROS* \\ Alessandra CASTRO ALVES** \\ Livia Souza PUGLIESE*** \\ Silvia Regina de Almeida REIS****
}

BARROS, S. G. de; CASTRO ALVES, A.; PUGLIESE, L. S.; REIS, S. R. de A. Contribuição ao estudo da cárie dentária
em crianças de 0-30 meses. Pesqui Odontol Bras, v. 15, n. 3, p. 215-222, jul./set. 2001.

Este estudo avaliou as condições de saúde bucal de 340 crianças de $0-30$ meses de idade $(21,3 \pm 5,6)$, sendo 54,4\% meninos, 45,6\% meninas, de 20 creches de Salvador, considerando lesões incipientes e relacionando-as a alguns fatores determinantes da cárie. Os exames foram realizados por um único examinador utilizando-se espelho, sonda e lanterna. Os dentes foram limpos, secos com gaze e as lesões classificadas de acordo com o grau de severidade em cinco níveis (CO-C4; ativa/inativa). Um questionário avaliou o conhecimento sobre a cárie, fatores de risco, instrução, renda familiar e uso de flúor. Foram incluídos 229 questionários (67,35\%). A análise dos dados foi realizada no Epi-info 6.02. Observou-se uma prevalência de cárie de 55,3\% quando todos os estágios da lesão foram considerados: $25 \%$ entre 0-12 meses; $51,18 \%$ entre $13-24$ meses; $71,03 \%$ entre $25-30$ meses $\left(\chi^{2}=25,31 ; p<0,01\right)$. Avaliando-se apenas manchas brancas ativas, 49,7\% das crianças mostraram-se afetadas e 17,6\%, apenas com lesões cavitadas. Das crianças afetadas, 90,96\% apresentavam apenas dentes anteriores afetados: $80 \%$ das lesões eram incipientes e $20 \%$, cavitadas. Não foi observada diferença significante entre sexos. O aumento da quantidade de biofilme dental mostrou associação positiva com a cárie nesta faixa etária $\left(\chi^{2}=67,61 ; p<0,01\right)$ e a porcentagem de crianças afetadas mostrou-se maior na presença de aleitamento noturno $\left(\chi^{2}=0,24 ; p=0,62\right)$. Foi observado um aumento da prevalência de cárie com a idade $\left(\chi^{2}=25,31 ; p<0,01\right)$ e com o número de dentes irrompidos $\left(\chi^{2}=122,95 ; p<0,01\right)$. Sugere-se atenção precoce à saúde bucal para o diagnóstico de lesões incipientes e adoção de medidas educativas e preventivas, incentivando mudanças na higiene bucal e dieta.

UNITERMOS: Cárie dentária; Dieta cariogênica; Saúde bucal.

\section{INTRODUÇÃO}

A cárie rampante relacionada ao hábito do aleitamento (peito ou mamadeira) durante o sono foi descrita pela primeira vez em 1862 pelo pediatra americano Jacobi ${ }^{11,13}$. Inicia-se com uma discreta desmineralização em mais de um dos incisivos superiores, progredindo de seis meses a um ano para lesões cavitadas ${ }^{23}$, podendo causar dor, infecção e perda prematura dos dentes decíduos ${ }^{2,17}$. O padrão característico inicial da cárie de aleitamento, segundo RIPA $^{13}$ (1978), é o quadro contrastante observado na mesma criança, com cárie severa nos incisivos superiores e incisivos inferiores intactos. A distribuição e severidade das lesões entre maxila e mandíbula estão relacionadas a 4 fatores: cronologia de erupção, duração e severidade de hábitos deletérios, fluxo salivar e padrão muscular de sucção ${ }^{8,13}$. Os incisivos estão expostos por um período mais prolongado ao aleitamento noturno e à higiene bucal deficiente do que os demais dentes. A continuidade destes hábitos acaba por envolver os outros dentes na seqüência de sua erupção ${ }^{13}$. O fluxo salivar e a freqüência de deglutição estão diminuídos durante o sono, permitindo uma estag-

* Cirurgiã-dentista.

** Professora Assistente de Odontopediatria da Faculdade de Odontologia da Universidade Federal da Bahia e Universidade Estadual de Feira de Santana.

*** Aluna de Graduação (Bolsista PET/SESU); ****Professora Doutora do Departamento de Diagnóstico e Terapêutica - Faculdade de Odontologia da Universidade Federal da Bahia. 
BARROS, S. G. de; CASTRO ALVES, A.; PUGLIESE, L. S.; REIS, S. R. de A. Contribuição ao estudo da cárie dentária em crianças de 0-30 meses. Pesqui Odontol Bras, v. 15, n. 3, p. 215-222, jul./set. 2001.

nação do líquido ao redor dos dentes, iniciando um processo contínuo de perdas minerais. O fluxo das glândulas salivares e o posicionamento da língua durante a sucção protegem os incisivos inferio$\operatorname{res}^{12,13,15}$.

Estudos sobre a cárie de mamadeira geralmente contemplam crianças entre 3 e 5 anos de idade. Esta afecção, contudo, pode manifestar-se antes mesmo dos 12 meses $^{21}$, sendo fundamental a execução de estudos em idades mais precoces. Alguns trabalhos, abordando faixas etárias menores e considerando lesões incipientes são apresentados no Quadro 1.

As características destrutivas deste tipo de cárie, atingindo uma idade precoce e em alta prevalência, tornam-na um padrão de cárie que requer atenção especial. O diagnóstico precoce das lesões iniciais, ainda em estágio reversível, e a avaliação dos fatores determinantes tornam-se fundamentais no estabelecimento de um tratamento mais simples, menos invasivo e de menor custo, envolvendo o uso de flúor e mudanças de comportamento com relação à dieta e a higiene bucal.

Este estudo teve o propósito de determinar a prevalência de cárie e a sua associação com condições de higiene bucal, alimentação e uso de fluoretos em crianças de 0-30 meses de idade das creches da Secretaria do Trabalho e Ação Social SETRAS/Governo do Estado da Bahia.

\section{MATERIAL E MÉTODO}

Após a aprovação do projeto de pesquisa pelo Comitê de Ética da Faculdade de Odontologia da Universidade Federal da Bahia, foi realizado um estudo de prevalência, envolvendo duas etapas: o exame da cavidade bucal de crianças entre 0-30 meses de idade e a aplicação de um questionário aos pais e/ou responsáveis. O questionário avaliou o perfil demográfico dos responsáveis (idade, renda, instrução) e fatores determinantes da cárie nesta faixa etária, como orientação e realização de higiene bucal, hábitos alimentares e exposição a fluoretos. Uma carta de autorização foi anexada ao questionário, explicando o motivo da pesquisa e os procedimentos a serem realizados com cada criança.

A amostra foi composta por 340 crianças saudáveis de 0-30 meses de idade $(21,3 \pm 5,6$ meses), freqüentadoras das creches com berçário, mantidas pela Secretaria do Trabalho e Ação Social SETRAS/Governo do Estado da Bahia.

Nenhuma das creches provia atenção odontológica às salas do berçário e as educadoras responsáveis por estas classes mostravam pouco ou nenhum conhecimento acerca da necessidade de higiene bucal nestas crianças. Quatro refeições diárias eram oferecidas no berçário diariamente: às 8 horas, ao meio-dia, às 14 horas e às 16 horas. A adição ou não de açúcar ao leite, mingau e suco era condicionada à decisão da coordenadora de

QUADRO 1 - Prevalência de cárie dentária em idade precoce.

\begin{tabular}{|c|c|c|c|c|}
\hline Autor & Idade das crianças & $\mathrm{N}^{\mathrm{o}}$ de crianças & $\%$ com cárie & ceo-d \\
\hline WENDT et al. ${ }^{24}(1991)$ & $\begin{array}{l}1 \text { ano } \\
2 \text { anos }\end{array}$ & $\begin{array}{l}632 \\
299\end{array}$ & $\begin{array}{l}0,5 \\
7,7\end{array}$ & $\begin{array}{l}- \\
-\end{array}$ \\
\hline WEINSTEIN et al. ${ }^{21}$ (1992) & $8-47$ meses & 125 & 29,6 & - \\
\hline SERWINT et al. ${ }^{16}(1993)$ & 18-36 meses & 110 & 20 & - \\
\hline TSUBOUCHI et al. ${ }^{18}$ (1994) & 18 meses & 638 & 13,7 & $0,27 * * *$ \\
\hline DOMOTO et al. ${ }^{5}$ (1994) & 9-34 meses & 130 & $35,7^{*}$ & - \\
\hline LEE et al..$^{9}(1994)$ & 24,4 meses & 77 & 35,1 & - \\
\hline HARRISON et al. ${ }^{7}$ (1997) & $\begin{array}{l}<18 \text { meses } \\
\geq 18 \text { meses }\end{array}$ & $\begin{array}{l}21 \\
39\end{array}$ & $\begin{array}{r}0 \\
64\end{array}$ & $\begin{array}{l}0,00^{* *} \\
8,4 * *\end{array}$ \\
\hline BÖNECKER et al. ${ }^{4}$ (1997) & $\begin{array}{l}0-1 \text { ano } \\
1-2 \text { anos } \\
2-3 \text { anos }\end{array}$ & $\begin{array}{l}157 \\
200 \\
191\end{array}$ & $\begin{array}{l}8,92 \\
34,5 \\
66,5\end{array}$ & $\begin{array}{l}0,16^{* * *} \text { e } 0,00^{* *} \\
0,87_{* * *}^{*} 0,23^{* *} \\
2,54 * * * \text { e } 1,33^{* *}\end{array}$ \\
\hline
\end{tabular}

* 7\% com pelo menos 1 incisivo superior cavitado; 30,4\% com ao menos 1 incisivo superior com mancha branca ativa.

** Sem inclusão de lesões incipientes (manchas brancas ativas).

*** Considerando-se manchas brancas ativas como cárie. 
BARROS, S. G. de; CASTRO ALVES, A.; PUGLIESE, L. S.; REIS, S. R. de A. Contribuição ao estudo da cárie dentária em crianças de 0-30 meses. Pesqui Odontol Bras, v. 15, n. 3, p. 215-222, jul./set. 2001.

cada creche. Em nenhuma das creches era freqüente o uso de mamadeiras e nenhum tipo de higiene bucal era realizada.

Os exames foram efetuados por um único examinador, previamente calibrado, com a criança deitada sobre uma maca, nas dependências das próprias creches, sob a iluminação de uma lanterna de luz branca posicionada pelo anotador perpendicularmente aos dentes. A limpeza das superfícies dentárias foi realizada com uma gaze umedecida em solução de água oxigenada diluída em água, numa proporção de 1:4, seguida da secagem com compressas secas e isolamento dos dentes $^{5,22}$.

O diagnóstico das lesões de cárie foi feito com espelho e o uso de sonda exploradora de ponta romba para verificar a presença de tecido amolecido, indicando lesão de cárie ativa. Não foi realizado exame radiográfico.

O exame era iniciado pelos dentes posteriores superiores e inferiores irrompidos, seguidos dos dentes anteriores inferiores e superiores. Esta seqüência favorecia a desidratação natural dos dentes ântero-superiores, onde avaliou-se tanto a presença de cavidades já estabelecidas, para determinação do ceo-d, como de lesões incipientes (manchas brancas ativas - m. b. a.). Os dentes que apresentavam hipoplasia de esmalte ou outras anomalias dentárias foram excluídos da amostra. Nos dentes posteriores e ântero-inferiores, devido a dificuldade para a secagem nas condições de realização do exame, observaram-se apenas as cavidades já instaladas.

A higiene bucal foi classificada em 3 escores, de acordo com a quantidade de biofilme dentário visível observado antes da limpeza dos dentes em:

- escore 1 - biofilme envolvendo até $1 / 3$ da coroa irrompida;

- escore 2 - biofilme em $2 / 3$ da coroa irrompida;

- escore 3 - biofilme cobrindo mais de $2 / 3$ da coroa irrompida.

Após a limpeza dos dentes, o grau de severidade das lesões de cárie foi classificado em 5 niveis, de acordo com o código proposto por TSUBOUCHI et al. ${ }^{19}$ (1994): C0 - mancha branca; C1 - cavidade em esmalte; C2 - cavidade em dentina; C3 - envolvimento pulpar; e C4 - fratura de coroa. Registrou-se também a atividade das lesões de cárie, classificando-as em:

- lesão ativa - manchas brancas rugosas e opacas no esmalte ou tecido dentinário amolecido de cor marrom-clara;
- lesão inativa - manchas brancas brilhantes ou pigmentadas e lisas e as cavidades com tecido dentinário escurecido e duro.

Os questionários foram entregues à coordenadora de cada unidade e recolhidos num prazo de 15 dias, sendo preenchidos pelos responsáveis, na própria creche, na presença de um funcionário.

A amostra foi classificada de acordo com a idade (0-12 meses, 13-24 meses e 25-30 meses) e, segundo o número de dentes irrompidos (até 8 dentes, 9-12 dentes e mais de 12 dentes).

A análise estatística dos dados foi realizada através do programa Epi-info 6.02. Foram utilizadas medidas de tendência central e variabilidade. A análise de medidas de associação entre cárie dentária e fatores como higiene bucal, orientação de higiene bucal, aleitamento noturno e exposição a fluoretos foi realizada através do teste não-paramétrico do qui-quadrado, com significância de $5 \%$.

\section{RESULTADOS}

Das 340 crianças examinadas, 54,4\% eram meninos e $45,6 \%$, meninas: 19 crianças tinham entre 0-12 meses, 213 entre 13-24 meses, e 108 entre 25 -30 meses de idade. A maioria da população incluída no estudo era de baixa renda $(72,5 \%$ dos pais/responsáveis recebia até um salário mínimo) e com baixo nivel educacional $(66,4 \%$ dos pais/responsáveis tinham apenas $\mathrm{o} 1^{\circ}$ grau e $12,7 \%$ nunca haviam freqüentado uma escola).

Foi encontrada uma prevalência de cárie de $55,3 \%$, quando todos os estágios de lesão foram considerados. Quando apenas as manchas brancas ativas foram incluídas, $49,7 \%$ das crianças mostravam-se afetadas, e 17,6\%, quando avaliaram-se apenas as lesões cavitadas. Observou-se um aumento na prevalência de cárie estatisticamente significante proporcional à idade (Gráfico 1) e ao número de dentes irrompidos (Gráfico 2).

A grande maioria das lesões $(99,63 \%)$ envolvia esmalte ou dentina (graus $\mathrm{C} 0, \mathrm{C} 1$ e C2), sendo representadas, principalmente, por manchas brancas ativas (COa). O Gráfico 3 mostra a freqüência das lesões de cárie de acordo com o grau de severidade e atividade.

Os dentes mais afetados foram, em ordem decrescente, os incisivos centrais e laterais superiores, molares inferiores, molares superiores e caninos superiores (Gráfico 4). Apenas 6 crianças não apresentavam nenhum dos incisivos superiores irrompidos. As lesões incipientes do tipo m.b.a. foram as mais freqüentes para os incisivos superio- 
BARROS, S. G. de; CASTRO ALVES, A.; PUGLIESE, L. S.; REIS, S. R. de A. Contribuição ao estudo da cárie dentária em crianças de 0-30 meses. Pesqui Odontol Bras, v. 15, n. 3, p. 215-222, jul./set. 2001.

res, representando $80 \%$ do total de lesões para este grupo de dentes.

O índice ceo-d encontrado foi de 0,35 para as crianças de 0-12 meses, 1,32 para 13-24 meses e 2,38 para 25-30 meses, quando foram consideradas as lesões incipientes. Definindo-se a cárie a partir do estágio de cavitação, o ceo-d, para as mesmas faixas etárias, foi de 0,15, 0,23 e 0,76.

O fator higiene bucal, avaliado durante o exame clínico, apresentou escore $1 \mathrm{em} 25,88 \%$ das crianças e escores 2 e 3 em $74,12 \%$ dos casos. O aumento da quantidade de biofilme (escores 2 ou 3 ) foi estatisticamente significante na contribuição para o desenvolvimento da cárie $\left(\chi^{2}=67,61\right.$; $\mathrm{p}<0,01)$ (Tabela 1).

Dos 340 questionários enviados, 229 (67,35\%) foram corretamente preenchidos e devolvidos, sendo incluídos no estudo. Destes, a grande maioria $(87,8 \%)$ foi respondida pelas mães, tendo $5,7 \%$ sido respondidos pelos pais e $6,6 \%$ por outros responsáveis. A idade média das mães/responsáveis

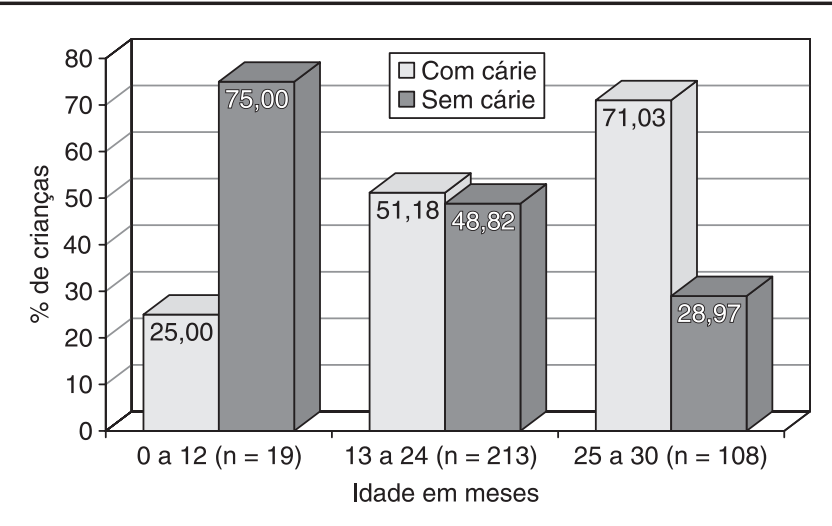

GRÁFICO 1 - Prevalência de cárie de acordo com a faixa etária $\left(\chi^{2}=25,31 ; \mathrm{p}<0,01\right)$.

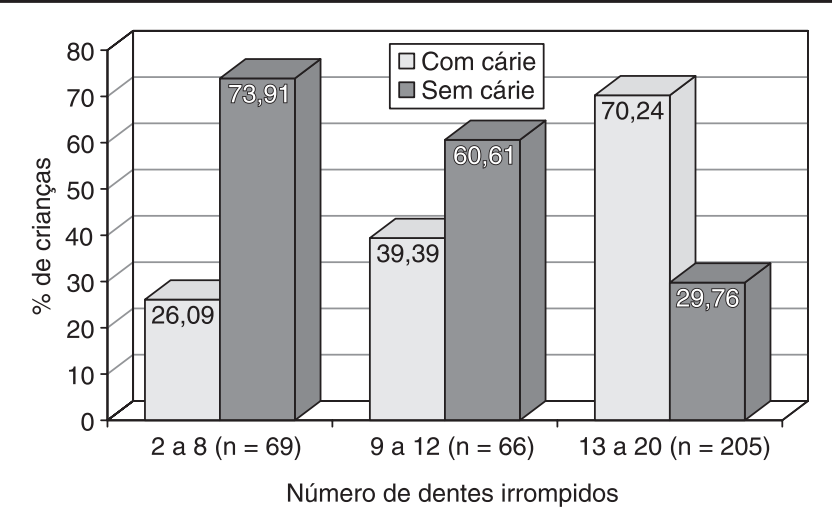

GRÁFICO 2 - Prevalência de cárie de acordo com o número de dentes irrompidos $\left(\chi^{2}=122,95 ; \mathrm{p}<0,01\right)$. foi de $27,96 \pm 7,92$ anos. Um total de $24 \%$ dos pais alegava ter recebido alguma orientação de saúde bucal. Aproximadamente $80 \%$ dos entrevistados consideraram a cárie como doença. A sua transmissibilidade, porém, só foi reconhecida por $48,7 \%$ dos pais. A limpeza da cavidade bucal das crianças após o aleitamento noturno foi relatada em $33,65 \%$ dos casos, sendo realizada em 51,94\% com escova de dentes. Nenhuma das crianças menores de 12 meses fazia uso de escova.

O hábito de aleitamento noturno era praticado por $127(55,46 \%)$ crianças. Na idade de 0-12 meses, $81,81 \%$ das crianças possuíam o hábito, reduzindo o percentual para $60,92 \%$ aos $13-24$ meses, e $38,8 \%$ aos $25-30$ meses, sendo estas diferenças estatisticamente significantes $\left(\chi^{2}=12,44 ; p<0,01\right)$ (Tabela 2).

Quanto à associação entre aleitamento noturno e cárie dentária, das $127(55,46 \%)$ crianças que recebiam aleitamento noturno, $65(28,39 \%)$ apresentavam alguma lesão de cárie, enquanto das $102(44,54 \%)$ que não possuíam o hábito, 54 $(23,58 \%)$ apresentavam-se livres de cárie (Tabela 3), mostrando que esta associação não foi estatisticamente significante $\left(\chi^{2}=0,24 ; p=0,62\right)$.

Apenas 22 crianças $(9,6 \%)$ faziam uso de chupetas umedecidas em substâncias cariogênicas e, destas, $50 \%$ apresentavam cárie. Não foi encontrada, contudo, qualquer significância para este hábito $\left(\chi^{2}=0,04 ; p=0,84\right)$.

A exposição a fluoretos limitou-se, na maioria dos casos, à água de abastecimento, sendo que $99,6 \%$ das crianças recebiam água fluoretada. A aplicação profissional e caseira de flúor foi relatada em $6,1 \%$ e $2,6 \%$ dos casos, respectivamente. A associação destes fatores com a prevalência de cá-

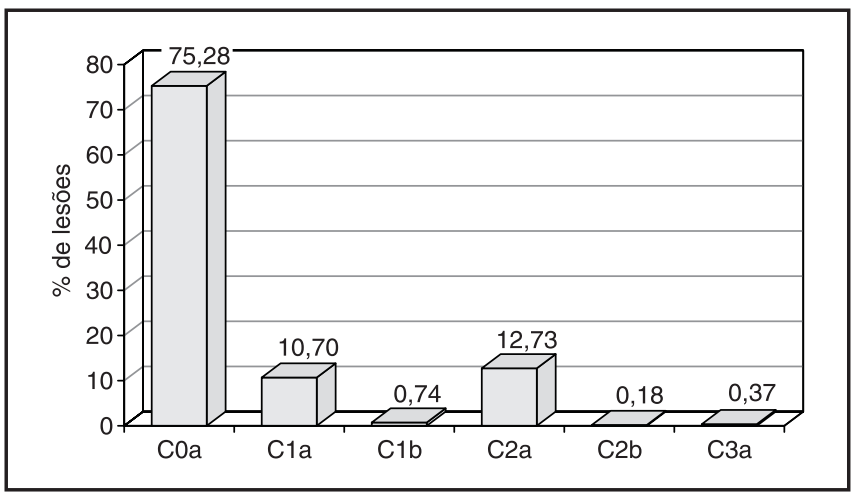

GRÁFICO 3 - Freqüência de lesões de cárie de acordo com o grau de atividade e severidade. $\mathrm{CO}=$ mancha branca; $\mathrm{C} 1$ = cavidade em esmalte; $\mathrm{C} 2$ = cavidade em dentina; $\mathrm{C} 3$ = envolvimento pulpar; $\mathrm{a}=$ lesão ativa; $\mathrm{b}=$ lesão inativa. 
BARROS, S. G. de; CASTRO ALVES, A.; PUGLIESE, L. S.; REIS, S. R. de A. Contribuição ao estudo da cárie dentária em crianças de 0-30 meses. Pesqui Odontol Bras, v. 15, n. 3, p. 215-222, jul./set. 2001.

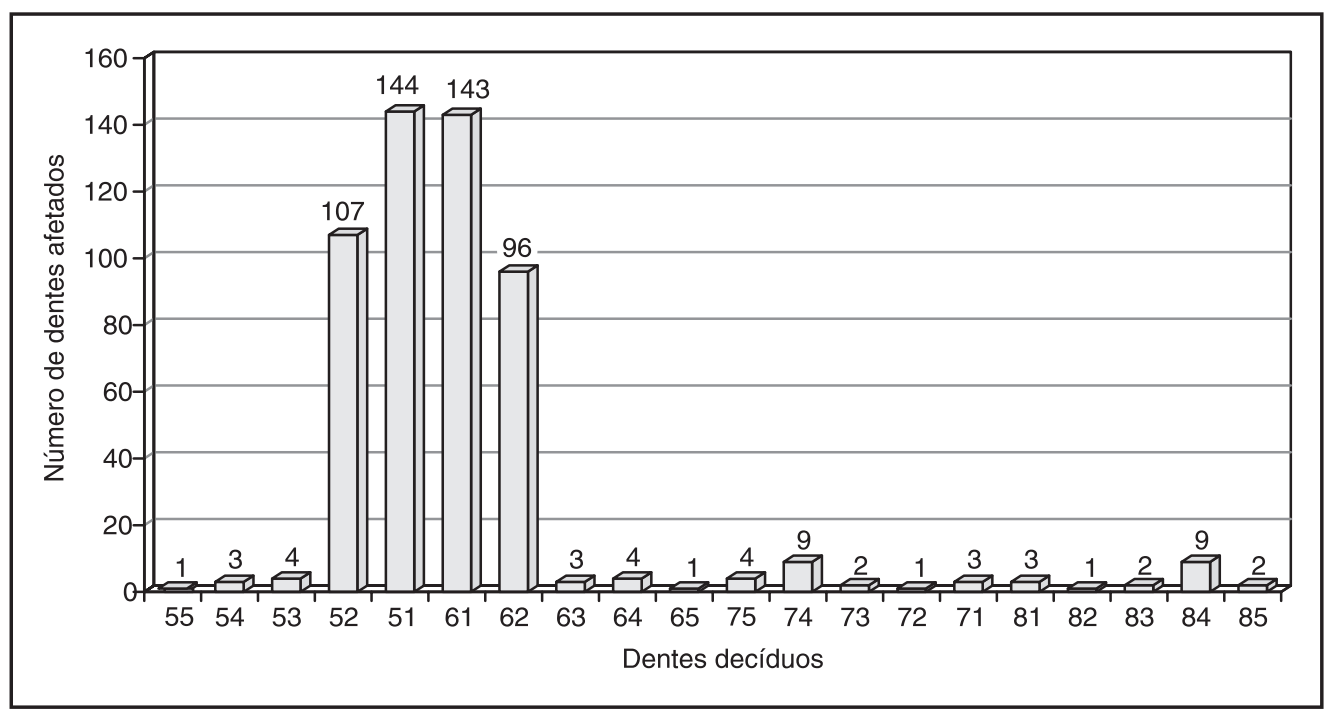

GRÁFICO 4 - Freqüência de dentes decíduos afetados.

TABELA 1 - Prevalência de cárie de acordo com o grau de higiene bucal.

\begin{tabular}{l|c|c|c}
\hline \hline Higiene bucal & Sem cárie & Com cárie & Total \\
\hline Escore 1 & $70(46,05 \%)$ & $18(9,57 \%)$ & $88(25,88 \%)$ \\
\hline Escore 2 & $73(48,03 \%)$ & $120(63,83 \%)$ & $193(56,77 \%)$ \\
\hline Escore 3 & $9(5,92 \%)$ & $50(26,60 \%)$ & $59(17,35 \%)$ \\
\hline Total & 152 & 188 & $340(100 \%)$ \\
\hline \hline
\end{tabular}

$\chi^{2}=67,61 ; p<0,01$.

rie não pôde ser avaliada devido à pequena parcela da população exposta.

\section{DISCUSSÃO}

As manchas brancas decorrentes da desmineralização do esmalte são sinais precoces da doença cárie e, quando não tratadas, podem evoluir para lesões cavitadas num período de seis meses a um ano $^{14,21}$. Segundo BERKOWITZ ${ }^{3}$ (1996), vários estudos enfocando a primeira infância seguem os critérios da OMS, definindo a cárie a partir do estágio de cavitação, desconsiderando as lesões incipientes e, muitas vezes, negligenciando sua instalação precoce.

Estudos incluindo manchas brancas ativas, como os realizados por DOMOTO et al. ${ }^{5}$ (1994), WEINSTEIN et al. ${ }^{22}$ (1994), TSUBOUCHI et al. ${ }^{18}$ (1994) e BÖNECKER et al. ${ }^{4}$ (1997) demonstram a instalação precoce da doença e a importância do diagnóstico e atenção em seus estágios iniciais, evitando o desenvolvimento de lesões mais severas em idade mais avançada. Existem, contudo, controvérsias quanto à inclusão da mancha branca
TABELA 2 - Aleitamento noturno por faixas etárias.

\begin{tabular}{|c|c|c|c|c|}
\hline \multirow{2}{*}{$\begin{array}{c}\text { Aleitamento } \\
\text { noturno }\end{array}$} & \multicolumn{3}{|c|}{ Idade } & \multirow[b]{2}{*}{ Total } \\
\hline & $\begin{array}{c}0-12 \\
\text { meses }\end{array}$ & $\begin{array}{l}13-24 \\
\text { meses }\end{array}$ & $\begin{array}{l}25-30 \\
\text { meses }\end{array}$ & \\
\hline Sim & $\begin{array}{c}9 \\
(3,93 \%)\end{array}$ & $\begin{array}{c}92 \\
(40,18 \%)\end{array}$ & $\begin{array}{c}26 \\
(11,35 \%)\end{array}$ & $\begin{array}{c}127 \\
(55,46 \%)\end{array}$ \\
\hline Não & $\begin{array}{c}2 \\
(0,87 \%)\end{array}$ & $\begin{array}{c}59 \\
(25,77 \%)\end{array}$ & $\begin{array}{c}41 \\
(17,90 \%)\end{array}$ & $\begin{array}{c}102 \\
(44,54 \%)\end{array}$ \\
\hline Total & 11 & 151 & 67 & $\begin{array}{c}229 \\
(100 \%)\end{array}$ \\
\hline
\end{tabular}

$\chi^{2}=12,44 ; p<0,01$

TABELA 3 - Associação entre cárie e aleitamento noturno.

\begin{tabular}{l|c|c|c}
\hline \hline $\begin{array}{c}\text { Aleitamento } \\
\text { noturno }\end{array}$ & Sem cárie & Com cárie & Total \\
\hline Sim & $62(27,07 \%)$ & $65(28,39 \%)$ & $127(55,46 \%)$ \\
\hline Não & $54(23,58 \%)$ & $48(20,96 \%)$ & $102(44,54 \%)$ \\
\hline Total & 116 & 113 & $229(100 \%)$ \\
\hline \hline
\end{tabular}

$\chi^{2}=0,24 ; p=0,62$.

nos índices de cárie em levantamentos epidemiológicos, uma vez que estas são passiveis de remineralização e reversão, podendo levar a distorções nos resultados ${ }^{3}$.

Neste estudo, optou-se pela inclusão da m.b.a., visto que se trata de uma lesão característica na faixa etária dos 10-20 meses de idade ${ }^{20}$, e por permitir uma avaliação da atividade de cárie e a im- 
BARROS, S. G. de; CASTRO ALVES, A.; PUGLIESE, L. S.; REIS, S. R. de A. Contribuição ao estudo da cárie dentária em crianças de 0-30 meses. Pesqui Odontol Bras, v. 15, n. 3, p. 215-222, jul./set. 2001.

plantação de medidas preventivas e curativas ainda em estágios precoces, tendo sido computado também o índice ceo-d, incluindo no componente "c" apenas as lesões cavitadas.

A metodologia empregada permitiu uma desidratação natural dos dentes ântero-superiores e boa iluminação, possibilitando o diagnóstico de lesões incipientes nestes dentes. A detecção da mancha branca é de fundamental importância na faixa etária enfocada neste estudo e a utilização da técnica empregada facilitou o acesso à população-alvo.

A alta freqüência de lesões incipientes $(75,28 \%)$ na amostra avaliada reforça a importância da inclusão da m.b.a. para estudos nesta faixa etária. Considerando-se as lesões incipientes, foi constatado ceo-d de 0,35 para a faixa etária de 0-12 meses, valor superior ao encontrado por BÖNECKER et al. ${ }^{4}$ (1997) para a mesma (ceo-d de 0,16).

A pequena exposição das crianças à fluorterapia, apesar de 99,6\% relatarem receber água de abastecimento fluoretada, pode ter contribuído para a alta prevalência de cárie, principalmente devido à provável pequena ingestão de água em vista da alimentação basicamente líquida e pastosa.

A prevalência de cárie aumentou com a idade e com o número de dentes irrompidos (Gráficos 1 e 2), provavelmente, devido ao número crescente de superficies dentárias expostas e à continuidade dos hábitos deletérios. A baixa freqüência de lesões inativas encontradas $(0,92 \%$ de lesões tipo b) (Gráfico 3) revela a ausência de mudanças de hábito e, conseqüentemente, progressão da doença e agravamento das lesões.

De acordo com ANDRADE; TORRES ${ }^{1}$ (1985), o leite humano é o mais adequado alimento para a criança e deve ser oferecido, pelo menos, até os seis meses de vida. O leite materno possui proteínas, gorduras, açúcares, vitaminas, sais minerais e anticorpos e, comprovadamente, protege os dentes da cárie. GONZÂLEZ-PÉREZ et al. ${ }^{6}$ (1992) concluíram que crianças com cárie de mamadeira apresentam curto período de aleitamento materno e, em conseqüência, quantidades menores de IgM no soro e de IgA na saliva. Porém, a exposição freqüente aumenta o potencial cariogênico do leite, observando-se maior experiência de cárie na presença de aleitamento noturno, principalmente, entre crianças com hábito de adormecer com a mamadeira ou no seio ${ }^{14}$. Mais da metade das crianças deste estudo recebiam aleitamento noturno (Tabelas 2 e 3), contudo não foi observada associação estatisticamente significante entre este hábito e ocorrência de cárie.

A limpeza dos dentes após a amamentação noturna, relatada nos questionários, não interferiu nos índices de cárie, mas, a avaliação clínica da higiene bucal mostrou relação significante entre estes fatores (Tabela 1).

$\mathrm{Na}$ amostra estudada, os dentes mais afetados foram os incisivos centrais e laterais superiores (Gráfico 4), respectivamente, concordando com o padrão de cárie relatado pela literatura ${ }^{9,10,12,14}$ acometendo os dentes em sua seqüência de erupção, estando os incisivos inferiores protegidos pela posição da língua durante o ato da sucção e pelo fluxo salivar intenso da região. Os incisivos superiores foram os dentes mais afetados: estas unidades exercem fundamental importância na estética e o seu comprometimento pode afetar o desenvolvimento psicológico e social da criança, provocando isolamento social e timidez. A dor e infecção causadas também contribuem para o quadro de alimentação incorreta, comprometendo o desenvolvimento físico da criança.

O quadro encontrado nesta faixa etária sugere um agravamento nas idades seguintes na ausência de medidas interceptoras e reparadoras. A continuidade deste estudo, avaliando propostas de intervenções coletivas nesta população, faz-se indispensável.

\section{CONCLUSÕES}

1. Foi encontrada uma alta prevalência de cárie na população estudada, quando se consideraram todos os estágios de lesão $(55,3 \%)$.

2. A prevalência de cárie aumentou significativamente na amostra estudada em função da idade $\left(\chi^{2}=25,31 ; p<0,01\right)$, do número de dentes irrompidos $\left(\chi^{2}=122,95\right.$; $\left.p<0,01\right)$ e com a inclusão das lesões incipientes (COa), para ambos os sexos.

3. Os incisivos superiores apresentaram maior prevalência de cárie para todos os graus de lesão.

4. A higiene bucal deficiente mostrou associação positiva com a presença de cárie nesta faixa etária $\left(\chi^{2}=67,61 ; p<0,01\right)$.

5. Não foi observada diferença estatisticamente significante quando avaliou-se a associação entre aleitamento noturno e presença de cárie $\left(\chi^{2}=0,24 ; p=0,62\right)$.

6. Sugere-se uma atenção à saúde bucal em idades menores através de métodos educativos e preventivos. 
BARROS, S. G. de; CASTRO ALVES, A.; PUGLIESE, L. S.; REIS, S. R. de A. Contribuição ao estudo da cárie dentária em crianças de 0-30 meses. Pesqui Odontol Bras, v. 15, n. 3, p. 215-222, jul./set. 2001.

BARRos, S. G. de; CASTRO ALVES, A.; PUGLIESE, L. S.; REIS, S. R. de A. Contribution to the study of dental caries in 0-30-month-old infants. Pesqui Odontol Bras, v. 15, n. 3, p. 215-222, jul./set. 2001.

This study evaluated the oral health conditions of 340 children, aged 0-30 months $(21.3 \pm 5.6)-54.4 \%$ of girls and $45.6 \%$ of boys - from 20 public day nurseries of Salvador (Brazil), as to the presence of incipient carious lesions. The exam was carried out by a single examiner, who utilized a mirror, a probe and a penlight. The teeth were wiped with gauzes in order to remove the dental plaque. A questionnaire was answered by the children's parents or caretakers in order to assess information regarding knowledge on caries, caries risk factors, socioeconomic status of the family and utilization of fluoride. Two hundred and twenty-nine answered questionnaires $(67.35 \%)$ were obtained. The observed lesions were classified in five stages, according to their severity (C0-C4; active/inactive). The data were analyzed using the Epi-info 6.02. The prevalence of caries was 55.3\% when all stages were registered: $25 \%$ for subjects aged $0-12$ months, $51.18 \%$ for subjects aged $13-24$ months and $71.03 \%$ for those aged $25-30$ months $\left(\chi^{2}=25.31, p<0.01\right)$. When only active white spots were considered, $49.7 \%$ of the children were affected; $17.6 \%$ of the children presented with cavitated lesions. Among the affected children, $90.96 \%$ had lesions only on anterior teeth: $80 \%$ of the lesions were white spots and $20 \%$, cavities. No significant difference was observed between genders. The increased amount of biofilm was positively associated with dental decay in toddlers $\left(\chi^{2}=67.61, p<0.01\right)$, and the number of affected children increased when the sleep-time nursing habit was present $\left(\chi^{2}=0.24, p=0.62\right)$. The prevalence of lesions increased with age and with the number of erupted teeth $\left(\chi^{2}=25.31, p<0.01 ; \chi^{2}=122.95, p<0.01\right)$. Early oral health attention, diagnosis of incipient lesions, as well as educative and preventive programs to change oral hygiene and dietary habits are suggested.

UNITERMS: Dental caries; Diet, cariogenic; Oral health.

\section{REFERÊNCIAS BIBLIOGRÁFICAS}

1. ANDRADE, M. G. N.; TORRES, I. A. Algumas considerações sobre o aleitamento materno no contexto social. Ars Cvrandi Odont, v. 11, n. 1, p. 38-41, jan./fev. 1985.

2. AYHAN, H.; SUSKAN, E.; YILDIRIM, S. The effect of nursing or rampant caries on height, body weight and head circumference. J Clin Pediatr Dent, v. 20, n. 3, p. 209-212, Spring 1996.

3. BERKOWITZ, R. J. Etiology of nursing caries: a microbiologic perspective. J Public Health Dent, v. 56, n. 1, p. 51-54, Spring 1996.

4. BÖNECKER, M. J. S.; GUEDES-PINTO, A. C.; WALTER, L. R. F. Prevalência, distribuição e grau de afecção de cárie dentária em crianças de 0 a 36 meses de idade. Rev Assoc Paul Cir Dent, v. 51, n. 6, p. 535-540, nov./dez. 1997.

5. DOMOTO, P.; WeINSTEIN, P.; LEROUX, B. et al. White spots caries in Mexican-American toddlers and parental preference for various strategies. J Dent Child, v. 61, n. 5-6, p. 342-346, Sept./Dec. 1994.

6. GONZÁLEZ-PÉREZ, S.; VENTURA-JUÁREZ, J.; CAMPOS-RODRIGGUES, R. Estudio sobre prevalencia de caries dental y caries rampante en población preescolar. Bol Med Hosp Infant Mex, v. 49, n. 11, p. 750-756, Nov. 1992.

7. HARRISON, R.; WONG, T.; EWAN, C. et al. Feeding practices and dental caries in an urban Canadian population of Vietnamese preschool children. J Dent Child, v. 64, n. 2, p. 112-117, Mar./Apr. 1997

8. KASTE, L. M.; MARIANOS, D.; CHANG, R.; PHIPPS, K. R. The assessment of nursing caries and its relationship to high caries in the permanent dentition. J Public Health Dent, v. 52, n. 2, p. 64-68, Winter 1992.

9. LEE, C.; REZAIAMIRA, N.; JEFFCOTT, E. et al. Teaching parents at WIC clinics to examine their high caries-risk babies. J Dent Child, v. 61, n. 5-6, p. 347-349, Sept./Dec. 1994.

10. MASSAO, J. M.; GIORDANO, D. V.; SUED, M. L. et al. Filosofia da Clínica de Bebês da UNIGRANRIO - RJ. Rev Bras Odontol, v. 53, n. 5, p. 6-13, set./out. 1996.

11. MILNES, A. R. Description and epidemiology of nursing caries. J Public Health Dent, v. 56, n. 1, p. 38-50, Spring 1996.

12. MULLER, M. Nursing-bottle syndrome: risk factors. J Dent Child, v. 63, n. 1, p. 42-50, Jan./Feb. 1996.

13. RIPA, L. W. Nursing habits and dental decay in infants: "nursing bottle caries". J Dent Child, v. 45, n. 4, p. 18-25, July/Aug. 1978.

14. RIPA, L. W. Nursing caries: a comprehensive review. Pediatr Dent, v. 10, n. 4, p. 268-282, Dec. 1988.

15. SCHWARTZ, S. S.; ROSIVACK, R. G.; MICHELOTTI, P. A child's sleeping habit as a cause of nursing caries. $\mathbf{J}$ Dent Child, v. 60, n. 1, p. 22-25, Jan./Feb. 1993.

16. SERWINT, J. R.; MUNGO, R.; NEGRETE, V. F. et al. Child-rearing practices and nursing caries. Pediatrics, v. 92, n. 2, p. 233-237, Aug. 1993.

17. SIENER, K.; ROTHMAN, D.; FARRAR, J. Soft drink logos on baby bottles: do they influence what is fed to children? $\mathbf{J}$ Dent Child, v. 64, n. 1, p. 55-60, Jan./Feb. 1997.

18. TSUBOUCHI, J.; HIGASHI, T.; SHIMONO, T. et al. A study of baby bottle tooth decay and risk factors for 18-month-old infants in rural Japan. J Dent Child, v. 61, n. 4, p. 293-298, July/Aug. 1994.

19. van HOUTE, J.; GIBBS, G.; BUTERA, C. Oral flora of children with "nursing bottle caries". J Dent Res, v. 61, n. 2, p. 382-385, Feb. 1982.

20. VEERKAMP, J. S. J.; WEERHEIJM, K. L. Nursing-bottle caries: the importance of a developmental perspective. $\mathbf{J}$ Dent Child, v. 62, n. 6, p. 381-386, Nov./Dec. 1995.

21. WEINSTEIN, P.; DOMOTO, P.; WOHLERS, K.; KODAY, M. 
BARROS, S. G. de; CASTRO ALVES, A.; PUGLIESE, L. S.; REIS, S. R. de A. Contribuição ao estudo da cárie dentária em crianças de 0-30 meses. Pesqui Odontol Bras, v. 15, n. 3, p. 215-222, jul./set. 2001.

Mexican-American parents with children at risk for baby bottle tooth decay: pilot study at a migrant farmworkers clinic. J Dent Child, v. 59, n. 5, p. 376-383, Sept./Oct. 1992.

22. WEINSTEIN, P.; DOMOTO, P.; KODAY, M.; LEROUX, B. Results of a promising open trial to prevent baby bottle tooth decay: a fluoride varnish study. J Dent Child, v. 61, n. 5-6, p. 338-341, Sept./Dec. 1994.

23. WEINSTEIN, P.; OBERG, D.; DOMOTO, P. K. et al. A pro- spective study of the feeding and brushing practices of WIC mothers: six- and twelve-month data and ethnicity and familial variables. J Dent Child, v. 63, n. 2, p. 113-117, Mar./Apr. 1996.

24. WENDT, L.-K.; HALLONSTEIN, A.-L.; KOCH, G. Dental caries in one and two-year-old children living in Sweden. Part I - a longitudinal study. Swed Dent J, v. 15, n. 1, p. 1-6, Jan. 1991.

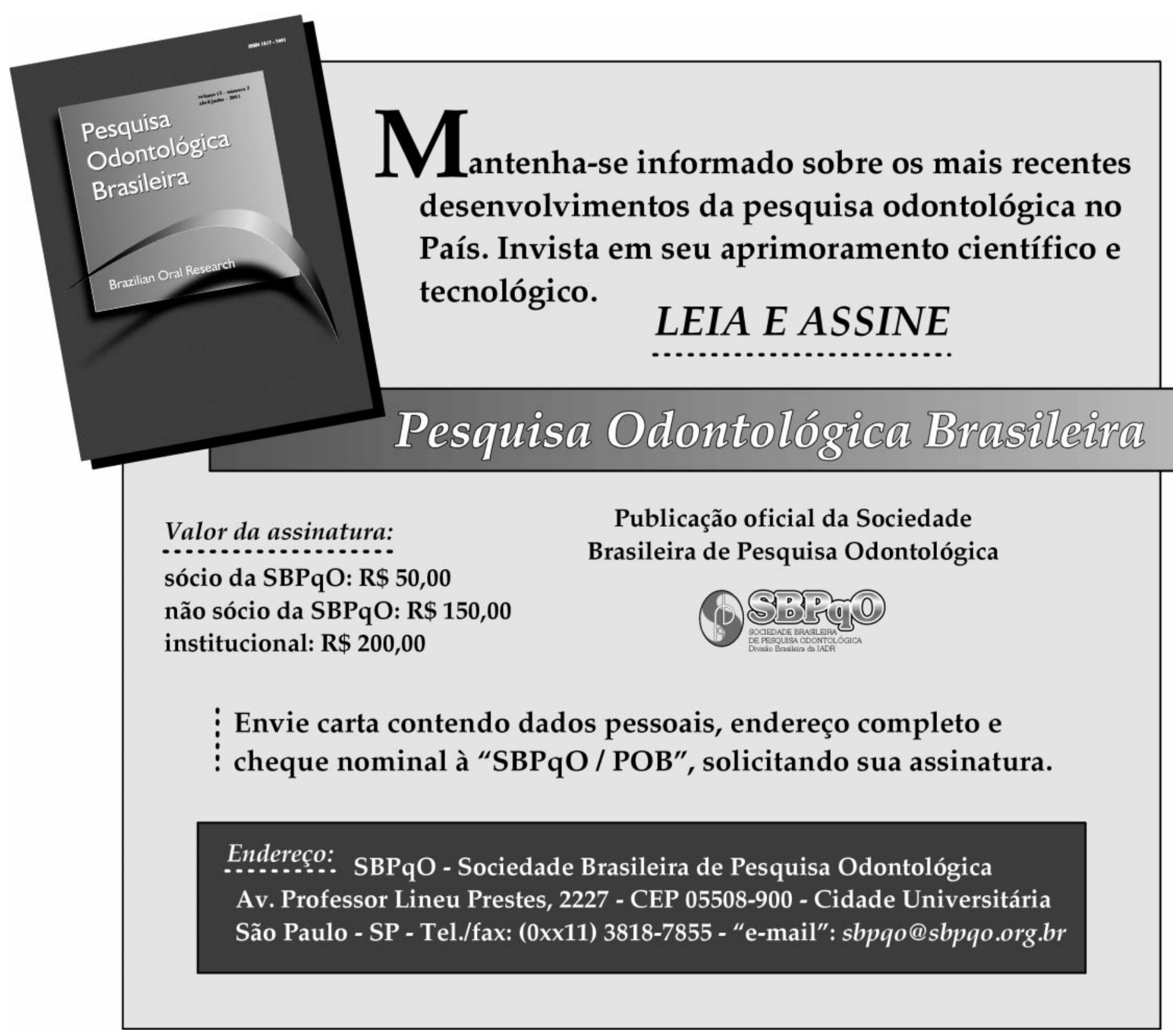

